\title{
High rate of bleeding and arterial thrombosis in COVID-19: Saudi multicenter study
}

\author{
Abdulrahman Al Raizah 1,2,3* Ahmed Al Askar ${ }^{1,2,3}$, Naila Shaheen ${ }^{3,4}$, Khalid Aldosari ${ }^{1,2}$, Mohamed Alnahdi ${ }^{1,2}$, \\ Musumadi Luhanga ${ }^{1,2}$, Turki Alshuaibi ${ }^{5}$, Wail Bajhmoum ${ }^{5}$, Khaled Alharbi ${ }^{5}$, Ghaida Alsahari ${ }^{5}$, Hadeel Algahtani ${ }^{5}$, \\ Eunice Alrayes ${ }^{6}$, Abdulrahim Basendwah? $^{7}$, Alia Abotaleb ${ }^{7}$ and Mosaad Almegren ${ }^{8}$
}

\begin{abstract}
Background: Several observational studies have reported the rate of venous and arterial thrombotic events in patients infected with COVID-19, with conflicting results. The aim of this study was to estimate the rate of thrombotic and bleeding events in hospitalized patients diagnosed with Coronavirus disease 2019 (COVID-19).

Methods: This was a multicenter study of 636 patients admitted between 20 March 2020 and 31 May 2020 with confirmed COVID-19 in four hospitals.
\end{abstract}

Results: Over a median length of stay in the non-ICU group of 7 days and of 19 days in the ICU group, twelve patients were diagnosed with Venous thromboembolism (VTE) (1.8\%) (95\% Cl, 1.1-3). The rate in the non-ICU group was $0.19 \%(95 \% \mathrm{Cl}, 0.04-0.84)$, and that in the ICU group was $10.3 \%(95 \% \mathrm{Cl}, 6.4-16.2)$. The overall rate of arterial event is $2.2 \%(95 \% \mathrm{Cl}, 1.4-3.3)$. The rates in the non-ICU and ICU groups were $0.94 \%(95 \% \mathrm{Cl}, 0.46-0.1 .9)$ and $8.4 \%(95 \% \mathrm{Cl}$, 5.0-14.0). The overall composite event rate was $2.9 \%(95 \% \mathrm{Cl}, 2.0-4.3)$. The composite event rates in the non-ICU and ICU groups were $0.94 \%(95 \% \mathrm{Cl}, 0.46-0.1 .9)$ and $13.2 \%(95 \% \mathrm{Cl}, 8.7-19.5)$. The overall rate of bleeding is $1.7 \%$ (95\% $\mathrm{Cl}, 1.0-2.8)$. The bleeding rate in the non-ICU group was $0.19 \%(95 \% \mathrm{Cl}, 0.04-0.84)$, and that in the ICU group was 9.4\% (95\% Cl, 5.7-15.1). The baseline D-dimer level was a significant risk factor for developing VTE $(\mathrm{OR} 1.31,95 \% \mathrm{Cl}$, $1.08-1.57, p=0.005)$ and composite events (OR 1.32, $95 \% \mathrm{Cl}, 1.12-1.55, p=0.0007)$.

Conclusions: In this study, we found that the VTE rates in hospitalized patients with COVID-19 might not be higher than expected. In contrast to the risk of $\mathrm{VTE}$, we found a high rate of arterial and bleeding complications in patients admitted to the ICU. An elevated D-dimer level at baseline could predict thrombotic complications in COVID-19 patients and may assist in the identification of these patients. Given the high rate of bleeding, the current study suggests that the intensification of anticoagulation therapy in COVID-19 patients beyond the standard of care be (Continued on next page)

\footnotetext{
* Correspondence: alzairaab@ngha.med.sa

'Division of Adult Hematology, Department of Oncology, King Abdulaziz Medical City, Ministry of National Guard Health Affairs, PO Box. 22490, 11426 Riyadh, Saudi Arabia

${ }^{2}$ King Abdullah International Medical Research Center, Saudi Society for Bone Marrow Transplant, Ministry of National Guard Health Affairs, Riyadh, Saudi Arabia

Full list of author information is available at the end of the article
}

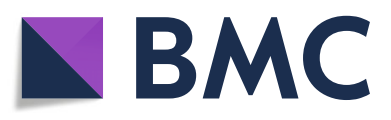

(- The Author(s). 2021 Open Access This article is licensed under a Creative Commons Attribution 4.0 International License, which permits use, sharing, adaptation, distribution and reproduction in any medium or format, as long as you give appropriate credit to the original author(s) and the source, provide a link to the Creative Commons licence, and indicate if changes were made. The images or other third party material in this article are included in the article's Creative Commons licence, unless indicated otherwise in a credit line to the material. If material is not included in the article's Creative Commons licence and your intended use is not permitted by statutory regulation or exceeds the permitted use, you will need to obtain permission directly from the copyright holder. To view a copy of this licence, visit http://creativecommons.org/licenses/by/4.0/. The Creative Commons Public Domain Dedication waiver (http://creativecommons.org/publicdomain/zero/1.0/) applies to the data made available in this article, unless otherwise stated in a credit line to the data. 
(Continued from previous page)

pursued with caution and would best be evaluated in a randomized controlled study.

Keywords: SARS-CoV-2, COVID-19, Coronavirus, Bleeding, Thrombosis, Venous thromboembolism, Arterial thrombosis, Stroke, Saudi

\section{Background}

Venous thromboembolism (VTE) is a leading cause of preventable hospital mortality [1]. Approximately 50\% of VTE events occurring outside of a hospital are due to recent hospitalization [2]. There are several risk factors for hospital acquired VTE, including acute illness, surgery, obesity, trauma, limited mobility, the presence of a central venous catheter, a history of thrombosis and old age [3]. The increased risk for VTE may persist for months after discharge [4]. It is estimated that $70 \%$ of hospital-acquired VTE can be prevented through pharmacological or mechanical methods; however, less than $50 \%$ of patients receive such preventive measures [57]. Coronavirus disease 2019 (COVID-19) is a global pandemic that has had a substantial impact on mortality, the health system and the economy $[8,9]$. Several observational studies have reported the rate of venous and arterial thrombotic events in patients infected with COVID-19, with conflicting results. Early studies showed an increased risk of thrombosis in COVID-19 patients, especially in critically ill patients, with a crude cumulative composite outcome of venous and arterial events of $57 \%$ [10-14] However, some studies reported a low rate of thrombotic events [15-18]. The aim of this multicenter study was to estimate the rate of thrombotic and bleeding events in hospitalized patients diagnosed with COVID-19 in Saudi Arabia.

\section{Methods}

\section{Patients and data collection}

We included consecutive patients aged $\geq 18$ years admitted between 20 March 2020 and 31 May 2020 with confirmed COVID-19. This study was conducted in four different hospitals, community-based and academic teaching hospitals. A confirmed COVID-19 case was defined as a positive reverse-transcriptase polymerase chain reaction (RT-PCR) test by nasal or oropharyngeal swab. Patients were excluded if they were transferred in or out from one of these four hospital to another hospitals. Patients also excluded if they were admitted for less than $24 \mathrm{~h}$. The patients were categorized as intensive care unit (ICU) patients or ward patients. ICU patients could be admitted to the ICU at any time during hospital admission. Data were collected retrospectively through a manual chart review from electronic and paper medical records from the first day of admission until discharge, death or the end of the data collection period (15 July 2020). The data were collected using a standardized form and included baseline characteristics, comorbidities, ICU admission, length of hospital stay, hospital discharge or death, bleeding and thrombotic events, dose and type of anticoagulation used, mechanical prophylaxis use and coagulation parameters. This study was approved by the Institutional Review Boards of all four hospitals. Due to the retrospective nature of this study, approval for written informed consent was waived.

\section{Outcomes}

The primary outcome was the rate of VTE. The secondary outcomes were the rate of arterial events, the rate of composite events (venous and arterial) and the rate of bleeding. VTE included all symptomatic or incidentally diagnosed cases of pulmonary embolism (PE), deep vein thrombosis (DVT) and thrombosis in unusual sites (cerebral, mesenteric, portal, splenic, hepatic, and renal veins). All VTEs were confirmed radiographically by appropriate imaging. We also included PE that was not confirmed radiologically but highly suspected by the treating physician based on a combination of clinical signs, symptoms, cardiac enzymes, electrocardiogram findings, and/or echocardiogram monitoring findings. Screening for VTE in asymptomatic patients was not performed. If more than on type of VTE occurred in the same patient, it was considered one event. Arterial events included cerebrovascular accidents (CVAs), mesenteric ischemia, and limb ischemia and were confirmed by the appropriate imaging modality. Myocardial infarction (MI) was diagnosed based on the suspicion of the attending physician using clinical criteria as well as biomarker elevations or electrocardiographic changes. Composite events were defined as any VTE or arterial event. Bleeding events were classified as major and nonmajor based on the definition proposed by the International Society of Thrombosis and Haemostasis (ISTH). Major bleeding was defined as fatal bleeding; symptomatic bleeding in a critical organ, such as intracranial, intraocular, intraspinal, intra-articular, retroperitoneal, or pericardial bleeding; intramuscular bleeding with compartment syndrome; bleeding leading to a decrease in the hemoglobin level of $20 \mathrm{~g} / \mathrm{L}$ or more; or the transfusion of 2 or more red blood cell units. All other bleeding episodes were considered nonmajor bleeding [19]. The baseline D-dimer level was defined as the first D-dimer level after admission. All D-dimer results are reported in fibrinogen equivalent units, with the normal level for D-dimer being less than $0.5 \mathrm{mcg} / \mathrm{ml}$. Two 
centers used the INNOVANCE D-dimer assay (Siemens), and the other 2 centers used the STA-Liatest assay (Stago).

\section{Statistical analysis}

Sex, nationality, history of cancer, history of thrombophilia, history of DVT, mechanical prophylaxis, enoxaparin dose, arterial thrombosis, location of the thrombus, lung infiltrate, and mortality are summarized as frequencies and percentages. The variables were compared in terms of the ICU and non-ICU groups using the chi-square/Fisher exact test. Data normality was determined with the Shapiro-Wilks test and is graphically displayed as a Q-Q plot. Age, cumulative comorbidities, length of hospital stay, and DVT duration were compared using the $t$ test. The rates of VTE, bleeding, arterial and composite events are summarized as proportions, with the corresponding $95 \%$ confidence intervals (CIs). The risk factors for developing VTE (DVT/PE/other venous thromboembolism) were identified using logistic regression. The independent variables age, sex, IMPROVE risk score, weight, baseline D-dimer level, baseline platelet count, and length of hospital stay were selected based on clinical judgment and univariate analyses. The results are reported as the odds ratios and the corresponding $95 \% \mathrm{CIs}$ and $\mathrm{p}$-values.

Overall survival was compared between patients who had a composite event vs. those who had no composite event using the Kaplan-Meier method with the log-rank test. A p-value less than 0.05 was considered significant. Statistical analyses were performed using SAS version 9.4 (SAS Institute, Cary, NC, USA).

\section{Results}

In total, 651 patients diagnosed with COVID-19 were enrolled in the current study, with a final sample of 636 patients after exclusion (Fig. 1).

The demographic and baseline characteristics of the patients by severity group (ICU vs. non-ICU) are displayed in Table 1 . The mean patient age was $49 \pm 16$ years, and the majority (71\%) were male. The mean BMI was $28 \pm 6 \mathrm{~kg} / \mathrm{m}^{2}$. One hundred and six patients (16.6\%) required ICU admission. The median length of hospitalization stay in the non-ICU group was 7 days,

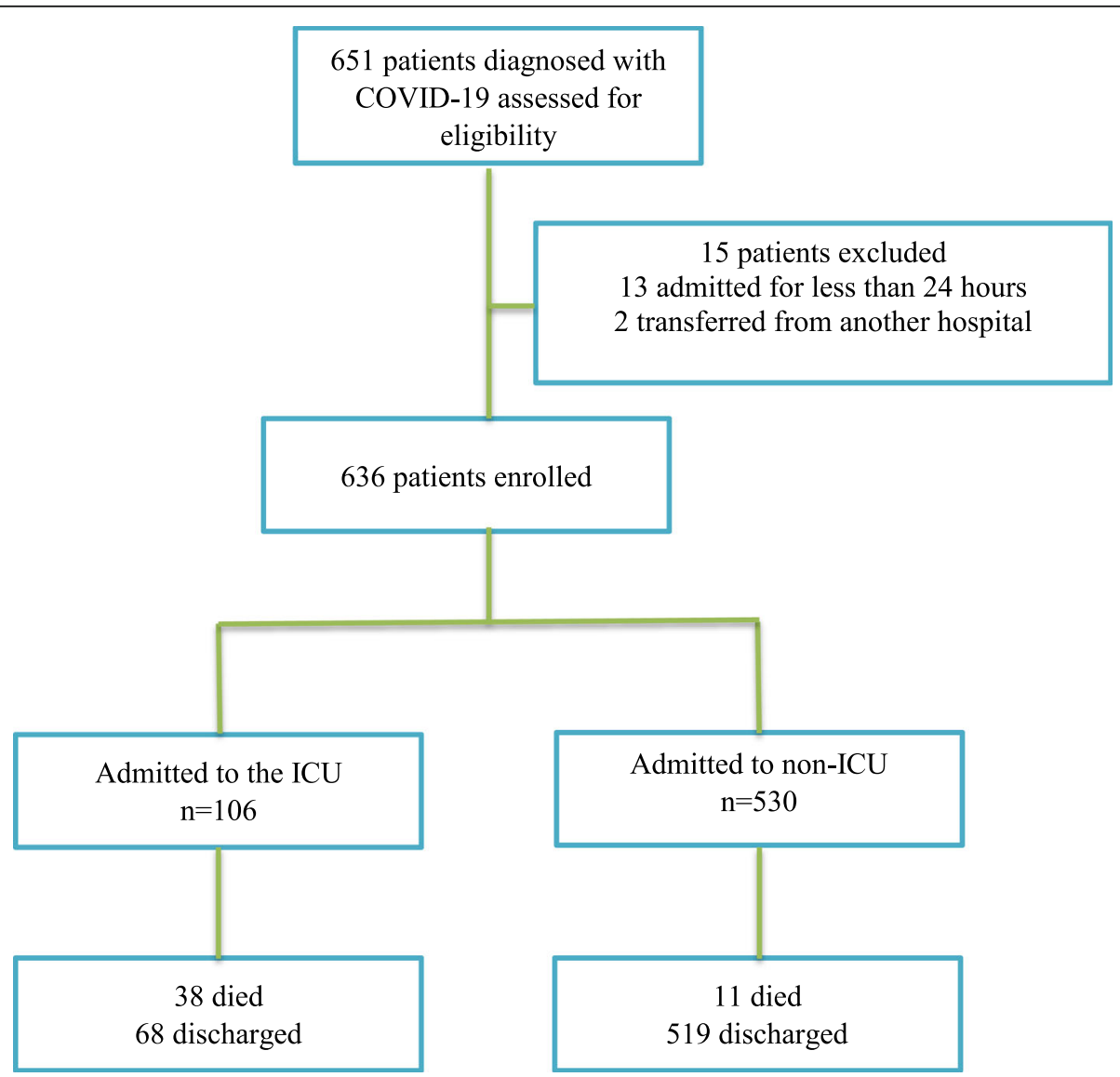

Fig. 1 Flow diagram of the study population 
Table 1 Demographics and Baseline Characteristics of the Population

\begin{tabular}{|c|c|c|c|c|}
\hline & $\begin{array}{l}\text { Overall } \\
n=636\end{array}$ & $\begin{array}{l}\text { Non-ICU } \\
n=530\end{array}$ & $\begin{array}{l}\text { ICU } \\
n=106\end{array}$ & $p$-value \\
\hline Age (mean $\pm S D)$ & $49 \pm 16$ & $47 \pm 16$ & $59 \pm 14$ & $<0.0001$ \\
\hline Male n (\%) & $456(71.7)$ & $371(70)$ & $85(80.2)$ & 0.033 \\
\hline Female $n(\%)$ & $180(28.3)$ & $159(30)$ & $21(19.8)$ & \\
\hline Weight (mean \pm SD) & $78.1 \pm 16.2$ & $77.2 \pm 15.1$ & $82.8 \pm 20.3$ & 0.007 \\
\hline $\mathrm{BMI}($ mean $\pm \mathrm{SD})$ & $28.4 \pm 6.0$ & $28.1 \pm 5.5$ & $17.3 \pm 7.8$ & 0.075 \\
\hline${ }^{a}$ Any comorbidities n (\%) & $303(47)$ & 205(38) & $98(92)$ & $<0.0001$ \\
\hline${ }^{\mathrm{b}}$ Active Cancer n (\%) & $12(1.9)$ & $9(1.7)$ & $3(2.8)$ & 0.432 \\
\hline History of Thrombophilia n (\%) & $3(0.47)$ & $1(0.19)$ & $2(1.8)$ & 0.073 \\
\hline History of DVT/PE n (\%) & $6(0.94)$ & $5(0.95)$ & $1(0.94)$ & 1.00 \\
\hline
\end{tabular}

${ }^{a}$ Comorbidities: DM, hypertension, coronary artery disease, stroke, bronchial asthma, COPD, heart failure, and ESRD

${ }^{\mathrm{b}}$ Active Cancer defined as patients on active treatment within last 6 months

whereas that in the ICU group was 19 days. At the end of data collection (15 July 2020), $7.7 \%(n=49)$ of participants had died, and the rest were discharged. The majority of patients $(90 \%, n=573)$ and more than $99 \%$ of those in the ICU group received pharmacological prophylaxis according to local hospital practice. The most frequently prescribed regimen was enoxaparin (40 mg once daily) (59.2\%). Some patients were prescribed more than one regimen during admission. Full-dose anticoagulation was prescribed for $6.1 \%$ of the sample due to a preexisting indication or empirically as part of COVID-19 management (Table 2).

\section{Thrombotic events}

VTE

Twelve patients were diagnosed with VTE (1.8\%) (95\% $\mathrm{CI}, 1.1-3)$. The rate in the non-ICU group was $0.19 \%$ (95\% CI, 0.04-0.84), and that in the ICU group was $10.3 \%$ (95\% CI, 6.4-16.2). The VTE rate in the non-ICU group was 21 events ( $95 \% \mathrm{CI}, 11-38$ ) per 10,000 persondays, and that in the ICU group was 83 events $(95 \% \mathrm{CI}$, 46-150) per 10,000 person-days. The cumulative incidence at 7, 14, and 21 days of VTE, arterial and bleeding outcomes are shown in Table 3.VTE was diagnosed a median of 13 days after admission. Six patients had PE, 3 had DVT (one was line related upper extremity), 2 had PE and

Table 2 Treatment Received

\begin{tabular}{|c|c|c|c|c|}
\hline Treatment & $\begin{array}{l}\text { Overall } \\
n=636 \\
n(\%)\end{array}$ & $\begin{array}{l}\text { Non-ICU } \\
n=530 \\
n(\%)\end{array}$ & $\begin{array}{l}\text { ICU } \\
n=106 \\
n(\%)\end{array}$ & $p$-value \\
\hline Mechanical prophylaxis & $6(0.94)$ & $3(0.57)$ & $3(2.8)$ & 0.016 \\
\hline Pharmacological prophylaxis & $573(90.0)$ & $468(88.3)$ & $105(99.0)$ & 0.0007 \\
\hline DOAC during admission & $9(1.4)$ & $7(1.3)$ & $2(1.8)$ & 0.649 \\
\hline Antiplatelet & $82(12.9)$ & $62(11.7)$ & $20(19.2)$ & 0.037 \\
\hline \multicolumn{5}{|l|}{ Enoxaparin Dose } \\
\hline $40 \mathrm{mg} O D$ & $377(59.2)$ & $332(62.6)$ & $45(42.4)$ & \multirow[t]{6}{*}{$<0.0001$} \\
\hline $40 \mathrm{mg} B D$ & $35(5.5)$ & $18(3.4)$ & $17(16.0)$ & \\
\hline $30 \mathrm{mg} O D$ & $7(1.1)$ & $3(0.57)$ & $4(3.7)$ & \\
\hline $30 \mathrm{mg} B D$ & $2(0.31)$ & 0 & $2(1.8)$ & \\
\hline Full dose & $28(4.4)$ & $20(3.7)$ & $8(7.5)$ & \\
\hline Other dose & $24(3.7)$ & $17(3.2)$ & $7(6.6)$ & \\
\hline \multicolumn{5}{|l|}{ Unfractionated Heparin Dose } \\
\hline 5000 TID & $41(6.4)$ & $23(4.3)$ & $18(16.9)$ & \multirow[t]{4}{*}{$<0.0001$} \\
\hline 5000 BID & $77(12.1)$ & $62(11.7)$ & $15(14.1)$ & \\
\hline Full dose & $11(1.7)$ & $6(1.1)$ & $5(4.7)$ & \\
\hline Other dose & $2(0.32)$ & $1(0.19)$ & $1(0.94)$ & \\
\hline
\end{tabular}


Table 3 Cumulative Incidence at 7, 14 and 21 Days

\begin{tabular}{cll}
\hline Variables/day & $\begin{array}{l}\text { All patients } \\
\%(95 \% \mathrm{Cl})\end{array}$ & $\begin{array}{l}\text { ICU } \\
\%(95 \% \mathrm{CI})\end{array}$ \\
\hline VTE & & \\
7 & $0.47(0.16-1.3)$ & $1.8(0.51-6.6)$ \\
14 & $0.94(0.43-2.0)$ & $4.7(2.0-10.5)$ \\
21 & $1.2(0.63-2.4)$ & $6.6(3.2-13.0)$ \\
Arterial & & \\
7 & $1.5(0.85-2.8)$ & $5.6(2.6-11.8)$ \\
14 & $2.0(1.1-3.4)$ & $7.5(3.8-14.1)$ \\
21 & $2.0(1.1-3.4)$ & $7.5(3.8-14.1)$ \\
Bleeding & & \\
7 & $0.16(0.02-0.88)$ & $0.94(0.16-5.1)$ \\
14 & $0.94(0.43-2.0)$ & $4.7(2.0-10.5)$ \\
21 & $1.2(0.63-2.4)$ & $6.6(3.2-13.0)$ \\
\hline
\end{tabular}

DVT, and one had portal vein thrombosis. Regarding thromboprophylaxis, 2 patients were not on prophylaxis prior to the event, 3 were on enoxaparin ( $40 \mathrm{mg}$ once daily), 3 were on UFH (5000 IU twice daily), 2 were on UFH (5000 IU TID), one was on enoxaparin (40 mg twice daily), and one was on fondaparinux (2.5 mg once daily). The type of all outcomes is displayed in Table 4.

\section{Arterial events}

Fourteen patients were diagnosed with an arterial event, with an overall rate of $2.2 \%$ (95\% CI, 1.4-3.3). The rates in the non-ICU and ICU groups were $0.94 \%$ (95\% CI, 0.46-0.1.9) and 8.4\% (95\% CI, 5.014.0). The arterial event rate was 71 events ( $95 \% \mathrm{CI}$, 37-137) per 10,000 person-days. The arterial event rates in the ICU and non-ICU groups were 218 events $(95 \% \mathrm{CI}, 104$ - 457) per 10,000 person-days and 21 (95\% CI, 5 - 85) per 10,000 person-days.

\section{Composite events}

The overall composite event rate was 2.9\% (95\% CI, 2.0-4.3). The composite event rates in the non-ICU and ICU groups were $0.94 \%$ (95\% CI, 0.46-0.1.9) and $13.2 \%$ (95\% CI, 8.7-19.5). The composite event rate was 25 events $(95 \%$ CI, 15 - 42) per 10,000 person-days. The composite event rates in the ICU and non-ICU groups were 85 events (95\% CI, 48 - 151) per 10,000 persondays and 4 (95\% CI, 1 - 19) per 10,000 person-days.

\section{Bleeding}

Eleven patients developed bleeding, with an overall rate of $1.7 \%$ (95\% CI, $1.0-2.8)$. The bleeding rate in the non-ICU group was $0.19 \%(95 \% \mathrm{CI}, 0.04-0.84)$, and that in the ICU group was $9.4 \%$ (95\% CI, 5.7-15.1). The overall bleeding rate was 22 events (95\% CI, 12 - 42) per 10,000 person-days, and the bleeding rate in the ICU group was 81 events (95\% CI, 42-157) per 10,000 person-days. Characteristic of bleeding are shown in Table 5.

\section{Risk factors for developing VTE/Composite events}

From the available data, the only risk factor that predicted VTE and the composite outcome was baseline Ddimer levels (Tables 6 and 7). The baseline D-dimer level was a significant risk factor for developing VTE (OR 1.31, $95 \%$ CI, 1.08-1.57, $p=0.005$ ) and composite events (OR 1.32, $95 \%$ CI, 1.12-1.55, $p=0.0007$ ).

\section{Mortality}

In total, 49 participants died, with an overall mortality rate of $7.7 \%$. The rate of mortality in the ICU group was $35.8 \%$, and that in the non-ICU group was $2 \%$. The participants were more likely to die if they were admitted to the ICU, older than 45 years, had a comorbidity, or had a composite event (Table 8).

Table 4 Outcome Data

\begin{tabular}{|c|c|c|c|c|}
\hline Variable & Overall & Non-ICU & ICU & $P$ value \\
\hline VTE \% (95\% Cl) & $1.8(1.1-3)$ & $0.19(0.04-0.84)$ & $10.3(6.4-16.2)$ & $<0.0001$ \\
\hline PE n & 8 & 0 & 8 & \\
\hline DVT n & 5 & 0 & 5 & \\
\hline Proximal upper $\mathrm{n}$ & 1 & 0 & 1 & \\
\hline Proximal lower $\mathrm{n}$ & 4 & 0 & 4 & \\
\hline Other VTE $n$ & 2 & 1 & 1 & \\
\hline Arterial \% (95\% CI) & $2.2(1.4-3.3)$ & $0.94(0.46-1.9)$ & $8.4(5.0-14.0)$ & $<0.0001$ \\
\hline CVA n & 10 & 4 & 6 & \\
\hline$M / n$ & 4 & 1 & 3 & \\
\hline Bleeding \% (95 \% CI) & $1.7(1.0-2.8)$ & $0.19(0.04-0.84)$ & $9.4(5.7-15.1)$ & $<0.0001$ \\
\hline Major bleeding $\mathrm{n}(\%)$ & 5 & 1 & 4 & \\
\hline Other bleeding n (\%) & 6 & 0 & 6 & \\
\hline
\end{tabular}


Table 5 Bleeding Characteristic

\begin{tabular}{lllll}
\hline Age & ICU & Site of bleeding & Severity & Anticoagulant at time of bleeding \\
\hline 45 & Yes & Lung & Major & UFH 5000 IU TID \\
62 & Yes & Lower Gl & Major & Enoxaparin 40 mg once \\
62 & Yes & Hematuria & Non major & Aspirin \\
61 & Yes & Cutaneous & Non major & UFH 5000 IU TID \\
73 & Yes & CNS & Major & Enoxaparin 40 mg once \\
64 & Yes & Cutaneous & Non major & Enoxaparin 40 mg once \\
59 & Yes & Cutaneous & Non major & Enoxaparin 40 mg once \\
62 & No & Musculoskeletal & Major & Enoxaparin 40 mg once \\
31 & Yes & CNS & Major & Enoxaparin 40 mg once \\
74 & Yes & Cutaneous & Non major & Enoxaparin $40 \mathrm{mg}$ BID \\
41 & Yes & Lower Gl & Non major & Full dose UFH \\
\hline
\end{tabular}

\section{Discussion}

In this multicenter study, we determined the thrombotic and bleeding complications of 636 COVID-19 patients. For VTE, all events except for one occurred in the ICU. The rate of VTE in the current study was much lower than that in previously published studies [10-14] but consistent with that in other studies [15-18]. In a multicenter study in the Netherlands $(n=184)$ [11] in which all patients were admitted to the ICU and received standardized doses of nadroparin and a dose escalation to 5700 IU BID at some point during admission in selected patients, the cumulative composite outcome of venous and arterial events was $49 \%$ when adjusting for a competing risk of death. Of the PE group, 19 of 65 were subsegmental. Another retrospective study [12] included 198 patients (74 patients in the ICU). All patients in the ICU were given thromboprophylaxis at standard or double doses. After a median follow-up of 7 days (IQR, 3-13), 39 patients (20\%) had VTE. After adjusting for a competing risk of death, the cumulative incidence of VTE on day 21 was $59 \%$ in the ICU group and $9.2 \%$ in the ward group. Screening for VTE was performed in some patients at regular intervals. In a prospective study conducted in France [13], 150 ICU patients with ARDS were compared to patients admitted for non-COVID-19

Table 6 Risk Factors of VTE

\begin{tabular}{llll}
\hline & Odds Ratio & $\mathbf{9 5} \% \mathbf{C l}$ & P-value \\
\hline Age & 1.01 & $0.95-1.07$ & 0.693 \\
Gender (Females vs. males) & 0.23 & $0.02-2.29$ & 0.214 \\
Improve Risk Score & 3.36 & $0.68-16.48$ & 0.134 \\
Weight & 1.01 & $0.98-1.06$ & 0.177 \\
Baseline D-Dimer & 1.31 & $1.08-1.58$ & 0.005 \\
Baseline platelet & 1.00 & $0.99-1.00$ & 0.416 \\
Length of hospital stay & 1.01 & $0.96-1.07$ & 0.547 \\
\hline
\end{tabular}

The logistic regression model with firth correction is based on probability of having VTE
ARDS. The primary outcomes were deep vein thrombosis, pulmonary embolism, myocardial infarction, mesenteric ischemia, lower limb ischemia, or cerebral ischemic attack. Propensity score matching was used, and it was determined that the COVID-19 ARDS patients had higher rates of thrombotic events than those with non-COVID-19 ARDS (11.7\% versus $2.1 \%$ ). In one of the largest studies that included 6513 patients (637 patients required mechanical ventilation), the rate of VTE within the hospitalized cohort was $3.1 \%$, and that in the subgroup of patients who required mechanical ventilation at any time during hospitalization was $7.2 \%$ [15]. In another multicenter retrospective study with 400 admitted COVID-19 patients, the VTE (confirmed or presumed) rates were $6 \%, 3.91 \%$ and $10.4 \%$ in all patients, noncritically ill patients and critically ill patients, respectively [16]. At the last ISTH meeting, a multicenter study that investigated the incidence of VTE and major bleeding in 3239 critically ill adults with COVID-19 was presented. The 14-day incidence of VTE was $6.3 \%$. It should be noted that $11.9 \%$ of the patients received therapeutic anticoagulation, though the reason was not

Table 7 Risk Factors of Composite Events

\begin{tabular}{|c|c|c|c|}
\hline & Odds Ratio & $95 \% \mathrm{Cl}$ & P-value \\
\hline Age & 1.03 & $0.97-1.10$ & 0.208 \\
\hline Gender (females vs. males) & 1.09 & $0.25-4.75$ & 0.905 \\
\hline Improve Risk Score & 1.57 & $0.40-6.12$ & 0.510 \\
\hline Weight & 0.98 & $0.94-1.02$ & 0.445 \\
\hline Length of hospital stay & 1.02 & $0.98-1.06$ & 0.262 \\
\hline Baseline platelets & 0.99 & $0.99-1.00$ & 0.653 \\
\hline Baseline D-Dimer & 1.32 & $1.12-1.55$ & 0.0007 \\
\hline aLung infiltrate (yes vs. no) & 1.91 & $0.44-8.21$ & 0.382 \\
\hline
\end{tabular}


Table 8 Risk Factors for Mortality in the Population

\begin{tabular}{llll}
\hline & $\begin{array}{l}\text { Hazard } \\
\text { Ratio }\end{array}$ & 95\% Cl & p-value \\
\hline Age ( $\geq 45$ years vs. less than 45 years) & 5.4 & $1.6-18.2$ & 0.006 \\
BMI ( $\geq 30$ vs. less than 30) & 1.1 & $0.60-2.0$ & 0.707 \\
Admitted to (ICU vs. non-ICU) & 5.0 & $2.3-10.8$ & $<0.0001$ \\
Cumulative comorbidities ( $\geq$ one vs. 0) & 1.6 & $0.8-3.3$ & 0.035 \\
Lung infiltrate (yes vs. no) & 1.2 & $0.6-2.6$ & 0.531 \\
Composite event (yes vs. no) & 2.3 & $1-5$ & 0.035 \\
\hline
\end{tabular}

mentioned [18]. The low rate of VTE in the current study compared to that of earlier studies could be partially explained by the different thresholds for admission to the hospital or ICU. In our study, the mean patient age was lower than that in other studies. The definition of thrombotic outcome was not the same as that in other studies. For example, some studies included extracorporeal circuit thrombosis and microvascular thrombosis [13]. The follow-up period was variable, and different prophylaxis regimens were used (in the current study, more than $90 \%$ of patients received pharmacological prophylaxis, and almost all patients in the ICU received prophylaxis). Additionally, there was no screening (Doppler US) for thrombotic complications, in contrast to other studies that reported a high rate [12]. Although we included suspected PE (not confirmed by imaging), some PE events could have been missed due to the difficulty associated with obtaining images in these patients, especially with the high mortality rate of $35 \%$ in the ICU group, which could be explained by missed PE events. Regardless of all of these possible causes, we found that the VTE rate of patients admitted to the ICU $(10.3 \%)$ was similar to that described in other non-COVID-19 critically ill populations $[20,21]$. What is also unusual is the very high PE-to-DVT ratio. Although PE may occur without DVT, it occurs in only $20 \%$ of non-COVID-19 patients [22]. This high ratio may be due to in situ pulmonary artery thrombosis, a different pathophysiology of COVID-19. In terms of arterial complications, the current study had a high rate of arterial events in the ICU group (8.4\%; $95 \%$ CI, 5.0-14.0). In the previously mentioned study [16], the rate of arterial thrombosis was $5.6 \%$ (95\% CI, 2.4-10.7\%) in critically ill patients, which is lower than the rate in our study. Interestingly, most of the events in the current study were CVAs. Most CVAs occurred in ICU patients (6/10), but there were four events occurred in non-ICU patients. Despite that minor transient ischemic attack with normal scans could be missed, this rate is still high. There is no good explanation for this rate except that this disease is a true prothrombotic situation.

The diagnosis of MI was based on physician judgments, taking into consideration a combination of clinical, laboratory and other evidence and was not confirmed by a coronary angiogram. This may partially contribute to the high rate of arterial events as well.

Regarding bleeding complications, the overall bleeding rate of $1.7 \%$ (95\% CI, $1.0-2.8)$ was similar to that in other COVID-19 studies [13, 18], but the rate of bleeding in the ICU group in the current study $(9.4 \%, 95 \%$ CI, 5.7-15.1) was slightly higher than the rate of bleeding reported in a previous study $7.6 \%(95 \% \mathrm{CI}, 3.9-$ $13.3 \%$ ) [16]. Most of the bleeding events were nonmajor, and if we calculated the rate of major bleeding only, it was $3.7 \%$ in the ICU group, which is similar to that of non-COVID-19 patients [23, 24]. We did not find correlation between the intensity of prophylactic regimen and bleeding as most of these bleeding events occurred with standard dose prophylactic regimens.

The difference in thrombotic outcomes in COVID-19 patients resulted in controversies in the guidelines of major societies for the prevention of these complications. The ISTH guidelines [25] suggested thromboprophylaxis with prophylactic-dose UFH or LMWH with the possibility of escalating to an intermediate-dose for high-risk patients and a $50 \%$ increase in the dose for obese patients. The CHEST guidelines [26] suggested the current standard-dose anticoagulant thromboprophylaxis over intensifying the dose to an intermediate or full treatment dose. In addition to an accurate estimate of the risk of thrombosis, there are areas requiring further investigation. There is limited evidence regarding the risk of bleeding in these patients. From the available evidence, the rate of major bleeding is variable and ranges from $<1 \%$ in ward patients to $7.6 \%$ in ICU patients $[16,18](8.4 \%$ in our study). This needs to be confirmed in well-designed prospective studies. A second issue is the case fatality rate of thrombotic and bleeding events, whether it is the same as for non-COVID-19 patients. This will support making a decision based on the risks and benefits of prophylaxis. There is also no definitive optimal method for assessing the risk for VTE. Would a risk assessment such as the Caprini, IMPROVE, or Padua model and others be able to risk stratify these patients? In terms of the diagnosis of VTE in COVID-19 patients, would a pretest probability using prediction models such as the Wells or Geneva model and biomarkers such as D-dimer be able to exclude VTE in these patients without the need for imaging studies (as it is known that most COVID-19 patients have a high Ddimer level)? Another unresolved issue is to determine the optimal dose of prophylactic anticoagulation and the duration of anticoagulation prophylaxis: should it be continued as an outpatient or not? In a large study of 1,877 patients [27], the rate of post discharge VTE was 4.8 per 1000 discharges over 42 days of followup, which is similar to the rate of dischargeassociated VTE in non-COVID-19 medical 
admissions, with an odds ratio for post discharge HAVTE associated with COVID-19 compared to nonCOVID-19 of 1.6 (95\% CI, 0.77-3.1). As of 15 August 2020, more than 10 randomized clinical trials in which varying intensities of anticoagulation therapy were used and different outcomes, such as the thrombosis rate, mortality and other complications, such as ICU admission, were investigated were listed on clinicaltrials.gov. The evidence generated through these studies is expected to strengthen the evidence related to this special population.

The strengths of the current study are as follows. The first strength is the multicenter setting of the study: this study was conducted in four different hospitals, community-based and academic teaching hospitals, representing most of the population and increasing the probability of generalizability. The second, strength is the relatively large sample size. The third strength is at the end of data collection, all the participants were discharged or died, whereas in other studies, some patients remained in the hospital, which could have resulted in an underestimation of the outcome.

This study was limited by its retrospective nature. Although we included not only confirmed but also suspected cases of VTE, some may have been missed, as there was no uniform protocol to exclude VTE in any of the four centers. All outcomes were not adjudicated. In addition, the diagnosis of MI was based on the judgment of the physician, who took into consideration a combination of clinical, laboratory and other evidence, and was not confirmed by a coronary angiogram. Another limitation is the small number of ICUadmitted patients compared to non-ICU patients, which is probably secondary to a low threshold for the admission of COVID-19 patients with mild symptoms in these hospitals. Because of the change of pharmacological prophylaxis on frequent bases for same patient, we do not have data for the duration of pharmacological prophylaxis that have been prescribed for each patient. Due to the retrospective nature and because there was no uniform protocol for management of COVID-19, there could be missing values. For instance, baseline D-Dimer was not available for all patients.

\section{Conclusions}

In this study, we found that the VTE rates in hospitalized patients with COVID-19 may not be higher than expected. In contrast to the risk of VTE, we found a high rate of arterial and bleeding complications in patients admitted to the ICU. An elevated D-dimer level at baseline could predict thrombotic complications in COVID-19 patients and may assist in the identification of these patients. Given the high rate of bleeding, the current study suggests that the intensification of anticoagulation therapy in COVID-19 patients beyond the standard of care be pursued with caution and is best evaluated in a randomized controlled study.

\section{Abbreviations}

ICU: Intensive care unit; VTE: Venous thromboembolism; COVID-

19: Coronavirus disease 2019; RT-PCR: Reverse-transcriptase polymerase chain reaction; PE: Pulmonary embolism; DVT: Deep vein thrombosis;

CVA: Cerebrovascular accident; MI: Myocardial infarction; DM: Diabetes mellites; ESRD: End stage renal disease; COPD: Chronic obstructive lung disease; GI: Gastrointestinal; CNS: Central nervous system;

UFH: Unfractionated heparin; ISTH: International Society of Thrombosis and Haemostasis; Cl: Confidence interval

\section{Acknowledgements}

Not applicable.

\section{Authors' contributions}

A Al Raizah wrote the first draft of the manuscript and contributed to the study design, creation of tables and figures, critical revision of the manuscript, and final approval; M Al Morgen contributed to the study design, creation of tables and figures, critical revision of the manuscript, and final approval; N Ashraf contributed to the study design, data analysis, creation of tables and figures, critical revision of the manuscript, and final approval; all other authors contributed to data collection, critical revision of the manuscript, and final approval.

\section{Funding \\ None.}

Availability of data and materials

The data used during the current study are available from the corresponding author on reasonable request.

\section{Ethics approval and consent to participate}

This study was approved by the Institutional Review Boards of all four hospitals. Due to the retrospective nature of this study, approval for written informed consent was waived.

\section{Consent for publication}

Not applicable.

\section{Competing interests}

The authors declare that they have no competing interests.

\section{Author details}

${ }^{1}$ Division of Adult Hematology, Department of Oncology, King Abdulaziz Medical City, Ministry of National Guard Health Affairs, PO Box. 22490, 11426 Riyadh, Saudi Arabia. ${ }^{2}$ King Abdullah International Medical Research Center, Saudi Society for Bone Marrow Transplant, Ministry of National Guard Health Affairs, Riyadh, Saudi Arabia. ${ }^{3}$ King Saud bin Abdulaziz University of Health Sciences, Riyadh, Saudi Arabia. ${ }^{4}$ Department of Biostatistics and Bioinformatics, King Abdullah International Medical Research Center, Riyadh, Saudi Arabia. ${ }^{5}$ Department of Medicine, King Fahd Hospital, Jeddah, Saudi Arabia. ${ }^{6}$ Department of Medicine, Prince Mohammed Bin Abdulaziz Hospital, Riyadh, Saudi Arabia. ${ }^{7}$ Oncology Division, Medicine Department, King Fahad Armed Forces Hospital, Jeddah, Mecca, Saudi Arabia. ${ }^{8}$ Department of Medicine, College of Medicine, Imam Mohammad Ibn Saud Islamic University, Riyadh, Saudi Arabia.

Received: 15 December 2020 Accepted: 16 February 2021 Published online: 03 March 2021

\section{References}

1. Society of Hospital Medicine. Maynard G, Stein J. Preventing hospitalacquired venous thromboembolism: a guide for effective quality improvement. Rockville: Agency for Healthcare Research and Quality, US Department of Health and Human Services; 2008.

2. Heit JA. Venous thromboembolism epidemiology: implications for prevention and management. In: Seminars in thrombosis and hemostasis. New York: Thieme Medical Publishers, Inc.; 2002. pp. 3-14.

3. Barbar S, Prandoni P. Scoring systems for estimating risk of venous thromboembolism in hospitalized medical patients. Semin Thromb Hemost. 2017:43:460-8. 
4. Hull RD, Merali T, Mills A, Stevenson AL, Liang J. Venous thromboembolism in elderly high-risk medical patients: time course of events and influence of risk factors. Clin Appl Thromb Hemost. 2013;19:357-62.

5. Zeidan AM, Streiff MB, Lau BD, Ahmed SR, Kraus PS, Hobson DB, et al. Impact of a venous thromboembolism prophylaxis "smart order set": improved compliance, fewer events. Am J Hematol. 2013;88:545-9.

6. Mitchell JD, Collen JF, Petteys S, Holley AB. A simple reminder system improves venous thromboembolism prophylaxis rates and reduces thrombotic events for hospitalized patients1. J Thromb Haemost. 2012;10: 236-43.

7. Lau BD, Haut ER. Practices to prevent venous thromboembolism: a brief review. BMJ Qual Saf. 2014;23:187-95.

8. Guan WJ, Ni ZY, Hu Y, Liang WH, Ou CQ, He JX, et al. Clinical characteristics of coronavirus disease 2019 in China. N Engl J Med. 2020;382:1708-20.

9. Zhou F, Yu T, Du R, Fan G, Liu Y, Liu Z, et al. Clinical course and risk factors for mortality of adult inpatients with COVID-19 in Wuhan, China: a retrospective cohort study. Lancet. 2020;395:1054-62.

10. Poissy J, Goutay J, Caplan M, Parmentier E, Duburcq T, Lassalle F, et al. Pulmonary embolism in patients with COVID-19: awareness of an increased prevalence. Circulation. 2020;142:184-6.

11. Klok FA, Kruip M, Van der Meer NJM, Arbous MS, Gommers D, Kant KM, et al. Confirmation of the high cumulative incidence of thrombotic complications in critically ill ICU patients with COVID-19: an updated analysis. Thromb Res. 2020;191:148-50.

12. Middeldorp S, Coppens M, Van Haaps TF, Foppen M, Vlaar AP, Müller MCA, et al. Incidence of venous thromboembolism in hospitalized patients with COVID-19. J Thromb Haemost. 2020;18:1995-2002.

13. Helms J, Tacquard C, Severac F, Leonard-Lorant I, Ohana M, Delabranche $X$, et al. High risk of thrombosis in patients with severe SARS-CoV-2 infection: a multicenter prospective cohort study. Intensive Care Med. 2020;46:1089-98.

14. Lodigiani C, lapichino G, Carenzo L, Cecconi M, Ferrazzi P, Sebastian T, et al. Venous and arterial thromboembolic complications in COVID-19 patients admitted to an academic hospital in Milan, Italy. Thromb Res. 2020;191:9-14.

15. Hill JB, Garcia D, Crowther M, Savage B, Peress S, Chang K, et al. Frequency of venous thromboembolism in 6513 patients with COVID-19: a retrospective study. Blood Adv. 2020;4:5373-7.

16. Al-Samkari H, Karp Leaf RS, Dzik WH, Carlson JCT, Fogerty AE, Waheed A, et al. COVID-19 and coagulation: bleeding and thrombotic manifestations of SARS-CoV-2 infection. Blood. 2020;136:489-500.

17. Mei F, Fan J, Yuan J, Liang Z, Wang K, Sun J, et al. Comparison of venous thromboembolism risks between COVID-19 pneumonia and community-acquired pneumonia patients. Arterioscler Thromb Vasc Biol. 2020;40:2332-7.

18. Al-Samkari H, Gupta S, Karp LR, Wang W, Rosovsky R, Bauer K, et al. Thrombosis, bleeding, and the effect of anticoagulation on survival in critically ill patients with COVID-19 in the United States. Res Pract Thromb Haemost. 2020;4.

19. Schulman S, Kearon C, Subcommittee on Control of Anticoagulation of the Scientific and Standardization Committee of the International Society on Thrombosis and Haemostasis. Definition of major bleeding in clinical investigations of antihemostatic medicinal products in non-surgical patients. J Thromb Haemost. 2005;3:692-4.

20. Zhang C, Zhang Z, Mi J, Wang X, Zou Y, Chen X, et al. The cumulative venous thromboembolism incidence and risk factors in intensive care patients receiving the guideline-recommended thromboprophylaxis. Med (Baltim). 2019;98:e15833.

21. Arabi YM, Al-Hameed F, Burns KEA, Mehta S, Alsolamy SJ, Alshahrani MS, et al. Adjunctive intermittent pneumatic compression for venous thromboprophylaxis. N Engl J Med. 2019;380:1305-15.

22. Palareti G, Antonucci E, Dentali F, Mastroiacovo D, Mumoli N, Pengo V, et al. Patients with isolated pulmonary embolism in comparison to those with deep venous thrombosis. Differences in characteristics and clinical evolution. Eur J Intern Med. 2019;69:64-70.

23. PROTECT Investigators for the Canadian Critical Care Trials Group and the Australian and New Zealand Intensive Care Society Clinical Trials Group. Cook D, Meade M, Guyatt G, Walter S, Heels-Ansdell D, et al. Dalteparin versus unfractionated heparin in critically ill patients. N Engl J Med. 2011; 364:1305-14.

24. Lauzier F, Arnold DM, Rabbat C, Heels-Ansdell D, Zarychanski R, Dodek $P$, et al. Risk factors and impact of major bleeding in critically ill patients receiving heparin thromboprophylaxis. Intensive Care Med. 2013;39:2135-43.

25. Spyropoulos AC, Levy JH, Ageno W, Connors JM, Hunt BJ, Iba T, et al. Scientific and standardization committee communication: clinical guidance on the diagnosis, prevention, and treatment of venous thromboembolism in hospitalized patients with COVID-19. J Thromb Haemost. 2020;18:1859-65.

26. Moores LK, Tritschler T, Brosnahan S, Carrier M, Collen JF, Doerschug K, et al. Prevention, diagnosis, and treatment of VTE in patients with coronavirus disease 2019: CHEST guideline and expert panel report. Chest. 2020;158: 1143-63.

27. Roberts LN, Whyte MB, Georgiou L, Giron G, Czuprynska J, Rea C, et al. Postdischarge venous thromboembolism following hospital admission with COVID-19. Blood. 2020;136:1347-50

\section{Publisher's Note}

Springer Nature remains neutral with regard to jurisdictional claims in published maps and institutional affiliations.
Ready to submit your research? Choose BMC and benefit from:

- fast, convenient online submission

- thorough peer review by experienced researchers in your field

- rapid publication on acceptance

- support for research data, including large and complex data types

- gold Open Access which fosters wider collaboration and increased citations

- maximum visibility for your research: over $100 \mathrm{M}$ website views per year

At BMC, research is always in progress.

Learn more biomedcentral.com/submissions 